tinin. We found that $47 \%$ and $39 \%$ of the patients had positive test results for aprotinin-specific $\operatorname{IgG}$ antibodies early and late after exposition. Not much is known about the precise immunologic sequel during an adverse reaction to aprotinin. Determination of aprotinin-specific $\operatorname{IgG}$ antibodies might be a useful clinical indicator to identify individuals at risk for anaphylactic reactions to aprotinin, but more precise methods are desirable.

\section{REFERENCES}

1. Lemmer JH, Stanford W, Bonney SL, Breen JF, Chomka EV, Eldredge WJ, et al. Aprotinin for coronary bypass operations: efficacy, safety, and influence on early saphenous vein graft patency - a multicenter, randomized, double-blind, placebocontrolled study. J Thorac Cardiovasc Surg 1994;107:543-51.

2. Diefenbach CM, Limpers AB, Lynch J, Ruskowski H, Jugert FK, Buzello W. Fatal anaphylactic shock after aprotinin reexposure in cardiac surgery. Anesth Analg 1995;80:830-1.

3. Dietrich W, Spaeth P, Ebell A, Richter JA. Incidence of anaphylactic reactions to aprotinin: analysis of 248 reexposures to aprotinin. J Thorac Cardiovasc Surg 1997;113:194-201.

4. Ruskowski H, Joos A, Kiefer H, Soeparwata R, Wendt G, Merk $\mathrm{H}$, et al. Untersuchungen zur Antigenität von Trasylol in der offenen Herzchirurgie. J Thorac Cardiovasc Surg 1993;41:86.

\title{
PRIMARY TRACHEAL SYNOVIAL CELL SARCOMA: A FIRST CASE REPORT
}

Anne T. Sykes, MD, ${ }^{a}$ Chris K. Rokkas, MD, ${ }^{a}$ Andre Kajdacsy-Balla, MD, ${ }^{b}$ and George B. Haasler, MD, ${ }^{a}$ Milwaukee, Wis.

Synovial cell sarcoma is a rare soft-tissue tumor comprising only $7 \%$ of all soft-tissue sarcomas, with fewer than $10 \%$ of those involving the head and neck. It has never been described involving the trachea as the primary site. We report here a case of primary tracheal synovial cell sarcoma and review the limited data available on diagnosis, prognosis, and treatment of this tumor.

Clinical summary. A 20-year-old white male college student with a 3-year history of exercise-induced asthma was being treated with bronchodilators. Progressive dyspnea, stridor, intermittent hemoptysis, and a $15 \mathrm{~kg}$ weight loss developed over a 3-month period. Coughing episodes elicited anterior chest pain radiating to the back. An episode of respiratory distress prompted a visit to the emergency department. Results of physical examination were remarkable for respiratory stridor and wheezing. The patient continued to have symptoms despite systemic steroid therapy. Bronchoscopy revealed a smooth, pale, soft tracheal tumor extending proximally to $3 \mathrm{~cm}$ below the true vocal cords, occupying most of the tracheal lumen. Computed tomography demonstrated a $3 \mathrm{~cm}$ intratracheal mass extending outside the tracheal wall, with its distal extension $5 \mathrm{~cm}$ above the carina (Fig. 1).

From the Departments of Cardiothoracic Surgery a and Pathology, ${ }^{\mathrm{b}}$ Medical College of Wisconsin, Milwaukee, Wis.

Received for publication Oct. 28, 1996; accepted for publication Jan. 8, 1997.

Address for reprints: George B. Haasler, MD, Medical College of Wisconsin, Department of Cardiothoracic Surgery, $9200 \mathrm{~W}$. Wisconsin Ave., Milwaukee, WI 53226-0099.

J Thorac Cardiovasc Surg 1997;114:678-80

Copyright $(1997$ by Mosby-Year Book, Inc.

$0022-5223 / 97 \$ 5.00+0 \quad \mathbf{1 2 / 5 4 / 8 0 2 3 3}$
There was neither clinical nor radiographic evidence of lymphadenopathy.

The patient underwent en bloc tumor excision with tracheal resection by a neck approach through a low collar incision. Intraoperative bronchoscopy revealed a normal distal tracheobronchial tree. Five tracheal rings with clear surgical margins of at least $1 \mathrm{~cm}$ were removed, and primary end-to-end anastomosis was performed. Grossly, the mass appeared well circumscribed, with transmural extension into the paratracheal region but without gross invasion into fat. The patient recovered uneventfully and was discharged to home on the fourth postoperative day without bronchodilators. Results of metastatic workup, including computed tomography of the chest, abdomen, and pelvis and a bone scan, were negative. $\mathrm{He}$ was referred to radiation oncology and received a total of 62 Gy external beam irradiation in 22 fractions of $180 \mathrm{cGy}$ and boost therapy in 12 fractions of $180 \mathrm{cGy}$. He has not been treated with adjuvant chemotherapy. The patient remains well 8 months after the operation.

Pathology. Histologically, the tumor showed biphasic growth. The pattern was composed mostly of ill-defined interweaving fascicles of monomorphic spindle cells but also showed numerous clear-cut foci of cuboidal cells forming pseudoglandular clusters (Fig. $2, a$ ). This biphasic pattern was even more obvious when immunohistochemical stains were used to show mutually exclusive vimentin-positive spindle cells and the epithelial component positive for low-molecular weight cytokeratin and carcinoembryonic antigen (Fig. 2,b). Numerous scattered mast cells were seen. Both components of the tumor stained negative for intracellular mucin (Alcian blue at pH 2.5, periodic acid-Schiff, and mucicarmine), argyrophilic granules (Grimelius stain), and immunohistochemically for chromogranin, S-100, B72.3, smooth-muscle actin, and desmin. 


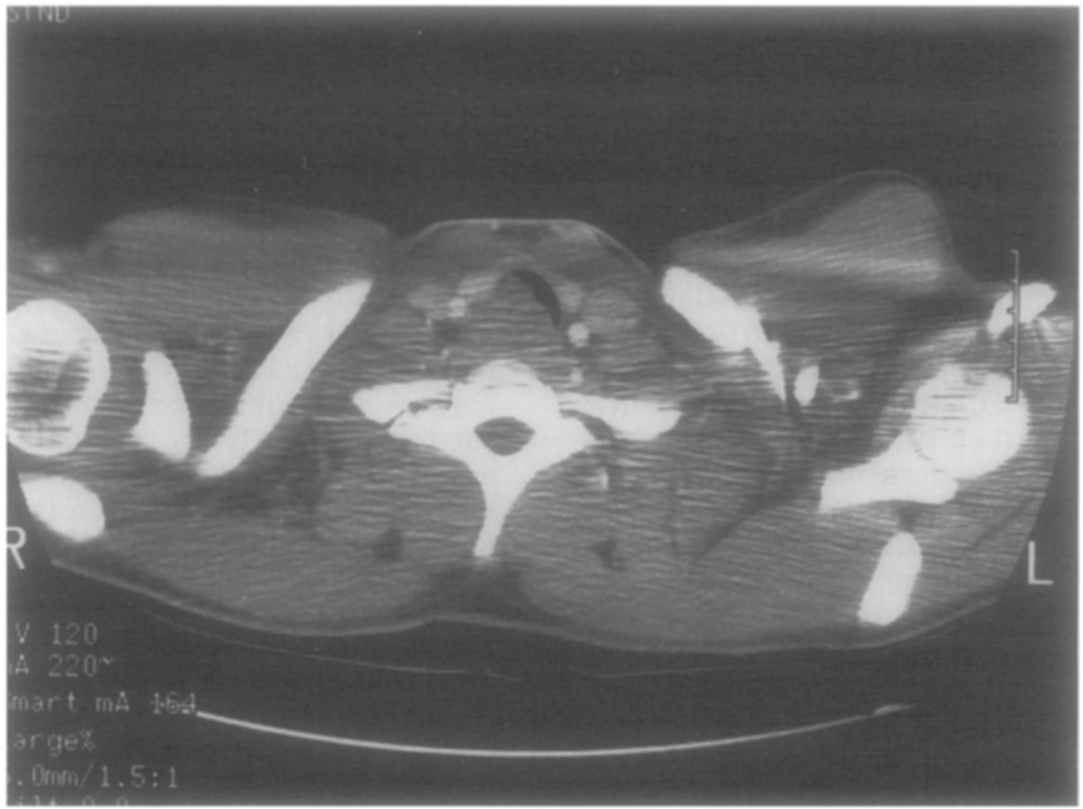

Fig. 1. Computed tomography demonstrates tracheal mass nearly obstructing lumen. Note extension outside normal lumen. Artifact caused by humeral heads. Each unit on the scale at the right represents 1 $\mathrm{cm} . R$, Right; $L$, left.
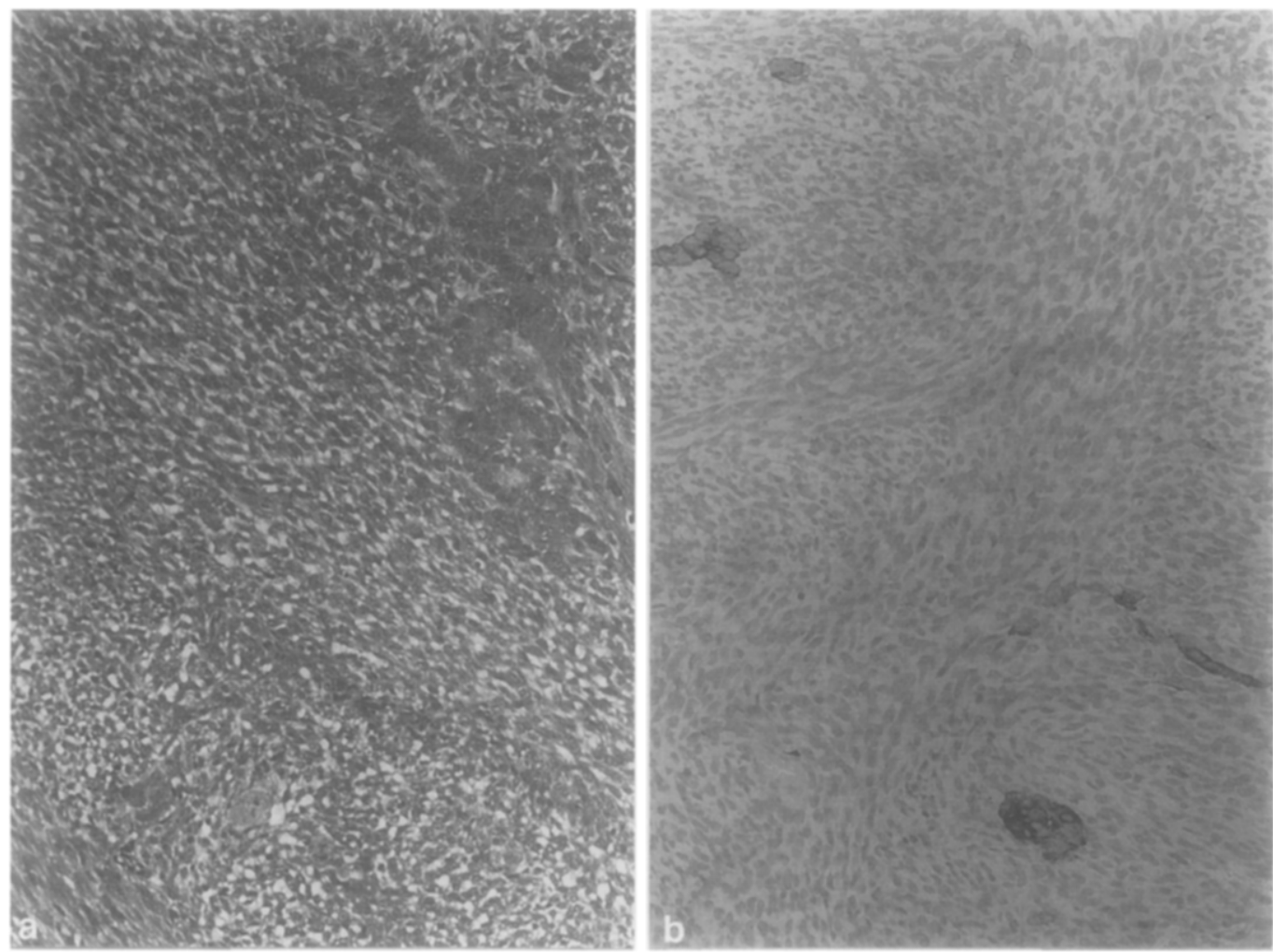

Fig. 2. Biphasic growth pattern characteristic of synovial cell sarcoma. a, Epithelial cell nests within sheets of spindle cells (Hematoxylin-eosinophil stain; $\times 500$ ). b, Spindle and epithelial cell structures confirmed with immunohistochemical staining (high-molecular weight cytokeratin stain; $\times 500$ ). 
Discussion. Synovial cell sarcoma is an exceedingly rare tumor in the head and neck. Jernstrom ${ }^{1}$ described the first synovial cell sarcoma of the head and neck in 1954. Fewer than 50 cases have been reported since, and fewer than $10 \%$ of these have involved the larynx or hypopharynx. They are commonly seen as large, painless neck masses in young men. Encroachment on adjacent structures may result in dysphagia, hoarseness, or airway obstruction. These symptoms often arise late and portend a poorer prognosis.

When occurring in the head and neck, synovial cell sarcomas are thought to arise from pleuripotential stem cells without any association with a synovial structure. They spread by way of direct extension along muscular and fascial planes and are rarely associated with nodal metastasis. ${ }^{2}$ Pulmonary metastatic disease has been described in some $40 \%$ of patients with head and neck synovial cell sarcomas, a mean of 30.8 months after resection. ${ }^{3}$ Although no studies have definitively demonstrated tumor size or histologic grade as prognostic factors, delay in diagnosis and narrow surgical margins have been shown to worsen outcome. ${ }^{3}$

The histologic diagnosis of synovial cell sarcoma is according to the classic biphasic histologic pattern of spindle cells mixed with glandular and epithelial elements, along with positive immunohistochemical staining for vimentin and cytokeratin. Other tumors, such as malignant fibrous histiocytoma, carcinoid, rhabdomyosarcoma, mesothelioma, pulmonary blastoma, and malignant glandular schwannoma, constitute the differential diagnosis and in our patient were ruled out by clinical, morphologic, and immunohistochemical differences.

Optimal treatment for head and neck synovial cell sarcomas is wide surgical excision of the tumor without lymphadenectomy. ${ }^{2,3}$ There are no data supporting the use of adjuvant chemotherapy. Radiation therapy has been shown to improve local control of head and neck synovial cell sarcomas if given in doses greater than 50 $\mathrm{Gy}^{3}$

Our patient's tumor was diagnosed late despite the fact that he had respiratory symptoms of 3 years' duration. His physical and radiographic examinations have ruled out another primary tumor and have excluded metastatic disease to date. With local recurrences of head and neck synovial cell sarcomas and metastases occurring as late as 62 months after surgical resection, ${ }^{2,3}$ long-term follow-up with computed tomography of the neck and chest is probably indicated. This patient will be followed up with bronchoscopy and computed tomography of the neck and chest every 6 months for a minimum of 5 years.

\section{REFERENCES}

1. Jernstrom P. Synovial sarcoma of the pharynx: report of a case. Am J Clin Pathol 1954;24:957-6 I.

2. Roth JA, Enzinger FM, Tannengaum M. Synovial sarcoma of the neck: a followup study of 24 cases. Cancer 1975;35:1243-53.

3. Amble FR, Olsen KD, Nascimento AG, Foote RL. Head and neck synovial cell sarcoma. Otolaryngo Head Neck Surg 1992;107;631-7.

\title{
IMMOBILIZED INSTRUMENT FOR MINIMALLY INVASIVE DIRECT CORONARY ARTERY BYPASS: MIDCAB DOUGHNUT
}

\author{
Masao Takahashi, MD, Shinichiro Yamamoto, MD, and Shigeki Tabata, MD, Fukui, Japan
}

So that satisfactory vessel immobilization can be achieved, enabling consistently accurate grafting during off-pump coronary artery bypass grafting (CABG), mechanical immobilizing devices ${ }^{1-3}$ have been developed along with immobilization methods including pharmacologic control of heart rate to produce bradycardia ${ }^{2}$

From the Department of Cardiovascular Surgery, Fukui Prefectural Hospital, Fukui, Japan.

Received for publication Feb. 26, 1997; accepted for publication May 13, 1997.

Address for reprints: Masao Takahashi, MD, Department of Cardiovascular Surgery, Fukui Prefectural Hospital, 2-8-1 Yotsui, Fukui, 910, Japan.

J Thorac Cardiovasc Surg 1997;114:680-2

Copyright (C) 1997 by Mosby-Year Book, Inc.

$0022-5223 / 97 \$ 5.00+0 \quad \mathbf{1 2 / 5 4 / 8 3 4 1 5}$ and induction of transient ventricular asystole with adenosine. Even with heart rates of about 40 beats/min, however, the technical demands of suturing are often difficult. In this report, we describe a new immobilizing instrument for use during minimally invasive $\mathrm{CABG}$ on the beating heart. With this instrument, a motionless and bloodless operative field can be achieved without occlusion of the distal coronary artery. The use of this instrument facilitates the new techniques of operating on the beating heart.

Techniques. The instrument, called a MIDCAB doughnut, consists of a double-bottomed silicone rubber dome and a suction tube that is supported with a handle. It has a simple structure, and its elastic firm material is thought to be safe and secure. The elastic dome has a small hole (14 to $16 \mathrm{~mm}$ in diameter) at the center through which the coronary artery that is being anastomosed can be positioned. The dimensions of the dome 